Olgu Sunumu/Case Report

\title{
Nörofibromatozisli bir olguda anestezik yaklaşım
}

Anesthetic approach in a patient with neurofibromatosis

Nilay Taş*, Sinan Yılmaz

Artvin Devlet Hastanesi, Anesteziyoloji Kliniği, Artvin

MAKALE BILGGILERI $\quad$ ÖZET

Makale Geçmişi:

Geliş 25/03/2009

Kabul $\quad 10 / 12 / 2009$

\section{* Yazışma Adresi:}

Nilay Taş

Artvin Devlet Hastanesi,

Ameliyathane, Artvin

e-mail: drnil.anest@hotmail.com

\section{Anahtar Kelimeler: \\ Nörofibromatozis \\ Zor Hava Yolu \\ Nörofibromlar \\ Rejyonel Anestezi \\ Multisistemik Tutulum}

\section{Key Words :}

Neurofibromatosis

Diffuculty Airway

Neurofibromas

Regional Anesthesia

Multysistemic Influence

\begin{abstract}
Nörofibromatozis, genetik ve multisistemik bir hastalıktır. Nörofibromatozis tip 1 (NF1) ve nörofibromatozis tip 2 (NF2) olmak üzere iki formu bulunur. NF1; yaygın nörofibromlar ve café au lait lekeleri ile karakterizedir. Santral sinir sistemini, hava yollarını, akciğer parankimini ve gögüs kafesini tutabilir. Bu grup hastalarda multisitemik tutulumdan dolayı anestezi uygulaması özellik taşır. Nörofibromlar üst hava yollarını tıkayabilir ve rejyonel anestezi sırasında spinal iğne deliğini kapatabilir. Burada hematürisi olan benign prostat hipertrofili bir erkek hastadaki anestezik yaklaşımımızı sunmak istedik.
\end{abstract}

J. Exp. Clin. Med., 2009; 26:202-205

\begin{abstract}
Neurofibromatosis is a multisystemic and genetically inherited disease. Two types are defined; Neurofibromatosis type 1 (NF 1) and Neurofibromatosis type 2 (NF2). NF 1 is characterized by neurofibromas and café au lait spots. Central nervous system, airways, lung parenchyma and thorax might be affected. Because of the multysistemic influence, anesthetic management requires special care in this group. Neurofibromas may obstruct the upper airways and close the spinal needle puncture during regional anesthesia. Here, we want to present our anesthetic management to a male patient with haematuria due to hypertrophy of prostate gland.

J. Exp. Clin. Med., 2009; 26:202-205
\end{abstract}

(C) 2009 OMÜ Tüm Hakları Saklıdır.

\section{Giriş}

Nörofibromatozis, otozomal dominant geçiş gösteren genetik, multisistemik bir hastalık olup, iki ayrı formu tanımlanmıştır. Bunlar Von Recklinghausen hastalığı olarak da bilinen nörofibromatozis tip 1 (NF1) ve nörofibromatozis tip 2 (NF2)' dir. NF2, daha nadir görülmektedir. NF1 ise tüm vücutta yaygın nörofibromlar, café au lait lekeleri denilen kahverengi deri lekeleri, optik gliomalar, benign melanotik iris hamartomları (Lisch nodülleri) ile seyreden ve pek çok sistemin etkilendiği formdur. Hastalığın en önemli karakteristik bulgusu olan nörofibromlar birden fazla sistemi etkileyerek anestezi uygulamasını güçleştirebilir. Nörofibromlar üst hava yollarını tıkayabilir ve rejyonal anestezi sırasında spinal iğne deliğini kapatabilir. Bu nedenle bu hasta grubunda anestezi uygulaması özellik taşımaktadır. Burada benign prostat hipertrofisi ön tanısı olup hematüri nedeniyle acil şartlarda ameliyata aldığımız bir erkek hastadaki anestezik yaklaşımımızı sunmak istedik.

\section{Olgu Sunumu}

Tüm vücudunda yaygın nörofibromlar ve çok sayıda değişik boyutlarda café au lait lekeleri bulunan 76 yaşinda, $60 \mathrm{~kg}$ erkek hasta, benign prostat hipertrofisi ve hematüri nedeniyle acil şartlarda operasyona alındı (Şek.1).

Preoperatif dönemde bakılan TSH değeri 0,003 $\mathrm{uIU} / \mathrm{ml}(0,35$ - 4,94) iken, FT3 ve FT4 değerleri normal sinırlardaydı, ayrıca kalsiyum değerinin $8,3 \mathrm{mg} / \mathrm{dl}$ olması dışında da herhangi bir biyokimyasal anormalliği mevcut değildi. Hb değeri; 10,3 g/dl, PLT değeri ise; $183000 / \mathrm{mm}^{3}$ idi. 


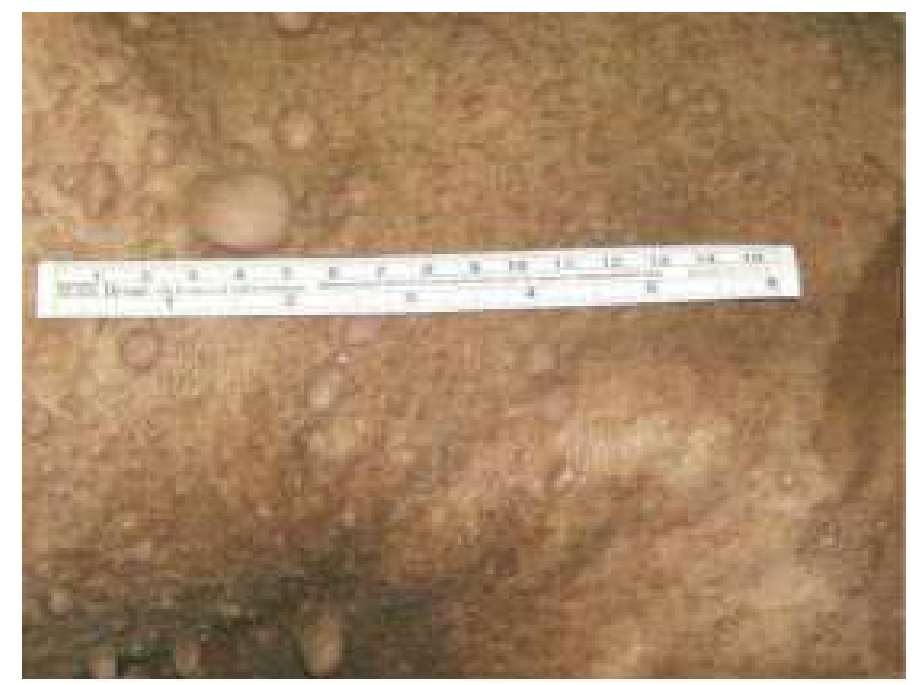

Şek. 1: Nörofibromlar.

Elektrokardiyografisinde nadir ventriküler ekstrasistolleri bulunan hasta, zaman zaman tansiyon yüksekliği dışında herhangi bir hastalığı olmadığını ve hiçbir ilaç kullanmadığını belirtmişti. Yapılan sorgulama ve preoperatif değerlendirmesinde de önemli bir bulguya rastlanmayan hastanın öyküsünden birinci derece yakınlarında da bu tip bir hastalık olduğu öğrenilmişti. Ayrıca bir kez lokal anestezi ile katarakt cerrahisi geçirmesinin dışında da operasyon veya anestezi öyküsü yoktu.

Hastaya ameliyathaneye geldiğinde önce rutin monitörizasyonlar (EKG, pulse oksimetre, noninvaziv arter basıncı) uygulandı. Arteriyel basınç değeri 140/95 mmHg, kalp hizı 88/dk idi. El sirtı venlerinden birine 18 G kanülle damar yolu açılıp, ilk saatte $680 \mathrm{ml} / \mathrm{saat}$, diğer saatlerde $280 \mathrm{ml} /$ saat şeklinde izotonik sodyum klorür infüzyonuna başlandı. Yüz maskesi ile $3 \mathrm{~L} / \mathrm{dk}$ 'dan oksijen verildi. Ardından sağ yan pozisyon verilip gerekli arıtım ve örtümden sonra L3-4 spinal aralığından 27 gauge spinal iğne ile $3,0 \mathrm{cc} \% 0,5$ lik hiperbarik bupivakain verilerek spinal anestezi uygulandi ( Şek. 2 ).

Sensoriyal blok seviyesi pinprick testi ile T7-8, motor blok ise Bromage skalasına göre 2 olarak tespit edildi. Yaklaşık $20 \mathrm{dk}$. sonra operasyon başlayınca, hastanın

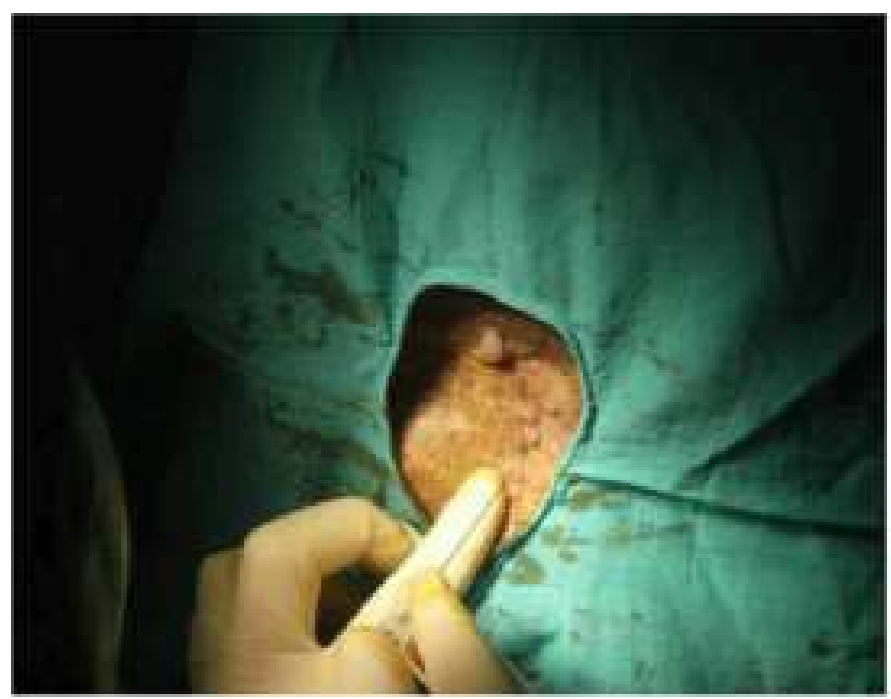

Şek. 2: Spinal blok uygulaması. ağrı duyduğunu söylemesi üzerine genel anesteziye geçme kararı alınd1. $7 \mathrm{mg} / \mathrm{kg}$ dozda tiyopental uygulamasını takiben 5 numaralı laryngeal maske yerleştirilerek hastaya genel anestezi verildi (Şek. 3).

Toplam akım $4 \mathrm{~L} / \mathrm{dk}$ olmak üzere $\% 50 \mathrm{O} 2+\% 50$ N2O karışımına \%2.0 konsantrasyonda sevofluran eklenerek idameye geçildi (Şek. 3). 1 saat süren operasyonun sonunda hasta sorunsuz olarak uyandırıld 1 ve derlenme odasındaki takibinin ardından servisine gönderildi. Hastada operasyon süresince hemodinamik açıdan bir problem tespit edilmedi. Sistolik arteriyel basınç ve diyastolik arteriyel basınç değerleri $120 / 70 \mathrm{mmHg}-140 / 90 \mathrm{mmHg}$ arasında, nabız değeri ise $85-95 / \mathrm{dk}$ civarında seyretti. Postoperatif dönemde de nörolojik ve anestezik açıdan herhangi bir komplikasyon gözlenmedi. Hastanın peroperatif olarak hemodinamik açıdan anormal seyreden bir değeri olmadı, hipertansif atak gözlenmedi.

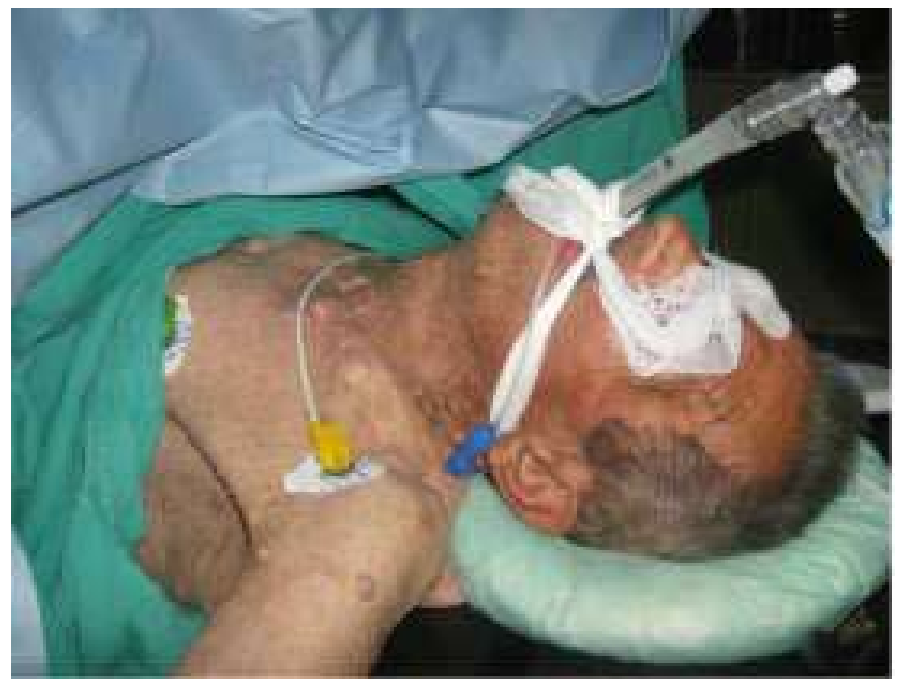

Şek. 3: Laryngeal maske uygulaması.

\section{Tartışma}

Nörofibromatozis, 2 tipi mevcut olan sistemik bir hastalıktır. NF Tip1 otozomal dominant geçen formu olup \% 100'e yakın oranda erişkinlerde görülür. (Katar ve ark., 2004; Çamsarı ve ark., 2006). Nörofibromlar hastalığın majör özelliklerindendir ve ileri derecede invaziv olup kas, kemik ve visseray1 da tutabilirler. (Kaymak ve ark., 2004) Nörofibromatozis multisitemik bir hastalıktır ve bu grup hastalarda anestezi uygulaması dikkat gerektirir. Anestezi yönetiminde mevcut sistemik anomalilerden dolayı güçlüklerle karşılaşılabilir ve hastanın anesteziye vereceği hemodinamik yanıtlarda da farklılıklar olabilir.

NF1 hava yollarını, akciğer parankimini ve gögüs kafesini tutabilir. (Çamsarı ve ark., 2006) Torasik belirtiler; nörofibromlar, interstisyel akciğer hastalığı, kostal deformasyonlar ve kifoskolyoz olarak sıralanabilir. Frenik sinir köklerinin tutulumu nedeniyle bilateral diyafragmatik paralizi gelişimi bildirilmiştir. (Hassoun ve ark., 2000; Çamsarıve ark., 2006). Bu nedenle hastalarda hem genel anestezi hem de rejyonel anestezi sırasında güçlüklerle karşılaşılma olasılığı artmakta olup, NF1 tanısı olan hastalarda 
preoperatif dönemde respiratuar sistemin ayrıntılı olarak değerlendirilmesi zorunludur. Hastalığın kardiyovaskuler tutulumunda ise hipertansiyon ön plandadır ve feokromositoma genel popülasyona oranla nörofibromatozis'te daha fazla görülmektedir. Bu grup hastalarda özellikle indüksiyon ve ekstübasyon aşamaları hipertansif kriz açısından en tehlikeli periyotlar olarak düşünülmeli, anestezi uygulaması sırasında kardiyovasküler stabilitenin devamını sağlamak ise en önemli amaç olmalıdır. Ayrıca aort koarktasyonu, kardiyomiyopati ve renovasküler hastalıklar da s1k görülmektedir. (Hirsch ve ark., 2001)

Nörofibromatozis Tip 1'li hastalarda kifoz, skolyoz gibi iskelet anomalileri varlığının yanı sıra spinal kordda ve sinir köklerinde nörofibromlar, hidrosefali ve psödoartroz görülebilir. (Hirsch ve ark., 2001, Crawford ve ark., 2007). İskelet anomalileri hem genel anestezi hem de rejyonel anestezi uygulamalarında önemli zorluklara yol açabilir.

Karakteristik bulgu olan nörofibromlar, orofarinks ve larinkste de bulunarak hava yolu obstruksiyonuna sebep olabilir. Bu durumda hava yolu yönetiminde, laringoskopi ve entübasyonda zorluk çıkması muhtemeldir. Von Recklinghausen nörofibromatozisli bir hastada dil tabanındaki nörofibromlar nedeniyle ciddi üst havayolu obstrüksiyonu gözlemlenmiştir ve bu hastada anestezi indüksiyonun takiben acil krikotiroidotomi gereksinimi doğmuştur. Öksürük, wheezing ve dispne semptomları olan hastalarda hava yolunu tıkayan nörofibromların varlığı akla gelmelidir. Hastalarda görülebilen mandibuler anomaliler ve makroglossi de havayolu yönetimini zorlaştıran diğer etkenlerdir. (Crozier ve ark., 1987; Hirsch ve ark., 2001; Irion ve ark., 2008).

Nörofibromatozisli hastalarda uygun anestezi yöntemine karar verebilmek, dikkatli bir sistemik değerlendirmeyi gerektirir. Bunun için öncelikle havayolu değerlendirilmesi yapılmalı, ardından solunumsal, kardiyovasküler ve santral sinir sistemi tutulumları ile vertebra anomalilerinin varlığ tespit edilmelidir. Kranial veya spinal tutulum olabileceği ve rejyonel anestezinin asemptomatik hastalarda mevcut nörolojik durumu bozabileceği düşünüldüğünde, genel anestezi tercih edilecek yöntem olarak görülebilir. Ancak bu durumda özellikle orofarinks ve larinkste yerleşimli nörofibromlardan dolayı güç entübasyon olasılığ 1 ve multisistemik tutulum nedeniyle hemodinamik açıdan stabil bir anestezi sağlamanın zor olabileceği akıldan ç1karılmamalıdır. Diğer taraftan nörofibromatozisli hastalarda süksinilkolin ve nondepolarizan nöromuskuler bloker ajanlara da değişken duyarlılık söz konusu olabilmektedir. Her ne kadar nöromuskuler blokerlere karşı anormal cevap riski minimal olarak belirtilmiş ise de halen nörofibromatozisli hastalarda anestezi uygulaması sırasında periferik sinir stimülatörü yoluyla rutin nöromuskuler monitörizasyon yapılmas1 önerilmektedir (Richardson ve ark., 1996; Hirsch ve ark., 2001).
Spinal blok nörofibromatozisli hastalarda vertebra anomalileri nedeniyle oldukça zordur. Dounas ve ark., (1995) CT taramaları ve klinik araştırmaları sonucunda spinal kordda negatif nörofibrom varlığını tespit ettikleri bir gebe hastada başarılı epidural anestezi uygulamışlardır. Esler ve ark., (2001) ise daha önceden tanı konmamış bir NF1 hastasına acil olarak doğum ağrısını gidermek amac1yla uyguladıkları epidural analjezi sırasında zorlukla karşılaştıklarını ve hastada epidural hematom geliştiğini bildirmişlerdir. Nöroaksiyal anestezide güvenlik, nörofibromların iğne açıklığını kapatabilme riski ve kifoskolyoz nedeniyle sınırlıdır ve teknik olarak da uygulama çok zordur (Şahin ve ark., 2003). Santral sinir sisteminde nörofibromların olmadığının ispat edilmesinden sonra nöroaksiyal anestezi endikasyonu koymanın doğru olduğu konusunda fikir birliği mevcuttur (Sakai ve ark., 2005).

Biz bu olguda, nörofibromatozis hastasında karş1laşılma ihtimali yüksek olan güç entübasyon olasıllğını düşünerek hastamıza öncelikle spinal blok uygulamayı uygun gördük. Olgumuzun daha önceden yapılan muayenesinde orofaringeal yapılarında gözle görülebilen yerlerde nörofibromlar bulunmamaktaydı ve TM mesafesi $\sim 6 \mathrm{~cm}$, Mallampati siniflaması ise Class II'ye uymaktaydı. Hastamızda preoperatif dönemde bölümünün uzmanı mevcut olmadığı için indirekt larinks muayenesi yapılamamıştı ve ayrica hastanemizde MR cihazı da bulunmamaktaydı. Ameliyat başladığı zaman hastanın ağrı duyduğunu ifade etmesi üzerine genel anestezi uygulamasına geçmeye karar verdik. Hastanemizin büyük merkezlere uzak oluşu ve güç entübasyon olasıllı̆ğna karşı1ık, elimizde mevcut bulunan malzemeler ile sıkıntı yaşanabileceğini düşünerek hastamıza laringeal maske yerleştirmeye karar verdik. Başarı bir laringeal maske uygulamasının ardından operasyon sorunsuz olarak sürdürüldü ve bir saat sonra operasyon sonlandığında hasta anesteziden uyandırıldı. Hastamız peroperatif olarak hemodinamik açıdan oldukça stabil bir dönem geçirdi, hipertansif atağı olmadı ve kardiyovaskuler bulgular açısından durumu stabildi. Bu durum bizi hastanın feokromositoma ile ilişkili olabileceği düşüncesinden uzaklaştırdı. Nörofibromatozis hastalarında başarı spinal blok uygulamaları bildirilmiş olmasına rağmen, spinal kordda nörofibromların var olabileceği spinal blokta başarısızlık olabileceğini de düşündürmelidir. Multisitemik bir hastalık oluşu nedeniyle Nörofibromatozisli hastalarda tüm anestezi yöntemleri dikkatli bir şekilde uygulanmal1dır ve bu tip hastalar anestezi açısından özelliği olan hastalar grubuna dahil edilmelidir.

Sonuç olarak; nörofibromatozisli bir hastada rejyonel anestezi veya genel anestezi yöntemleri arasında karar verirken hastanın göreceği yarar göz ardı edilmemeli, mevcut olanaklar gözden geçirilmeli ve preoperatif dönemde tam bir sistemik değerlendirme yapılmalıdır. Spinal kordun preoperatif değerlendirilmesi, nöroaksiyal anestezi yönündeki kararı; hastanın mevcut hemodinamik durumu 
ve multisistemik tutulum özellikleri ise genel anestezi yönündeki kararı etkiler. Uygulanacak anestezi yönteminde karar ne olursa olsun, bu hastalarda güç entübasyon ola- s1lığının yüksek olduğu düşünülerek havayolu güvenliğini sağlayacak tüm hazırlıklar yapıldıktan sonra planlanan anestezi uygulamasına geçilmelidir.

\section{Kaynaklar}

Crawford, A.H., Herrera-Soto, J., 2007. Scoliosis associated with neurofibromatosis. Orthop. Clin. North Am. 38, 553-562.

Crozier, W.C., 1987. Upper airway obstruction in neurofibromatosis. Anaesthesia. 42, 1209-1211.

Çamsarı, G., Gür, A., Özkan, G., Bakan, N.D., Zengin, F., Külcü, A. 2006. Nörofibromatoziste torasik bulgular. Tüberküloz ve Toraks Derg.. 54, 267-272.

Dounas, M., Mercier, F.J., Lhuissier, C., Benhamou, D., 1995. Epidural analgesia for labour in a parturient with neurofibromatosis. Can. J. Anaesth. 42, 420-422.

Esler, M.D., Durbridge, J., Kirby, S., 2001. Epidural haematoma after dural puncture in a parturient with neurofibromatosis. British J. Anaesth. 87, 932-934.

Hassoun, P.M., Celli, B.R., 2000. Bilateral diaphragm paralysis secondary to central von Recklinghausen's disease. Chest; April. $117,1196-1200$

Hirsch, N.P., Murphy, A., Radcliffe, J.J., 2001. Neurofibromatosis: Clinical presentations and anesthetic implications. British J. Anaesth. 86, 555-564.

Irion, K.L., Gasparetto, T.D., Marchiori, E., Hochhegger, B., Rubin, A.S., 2008. Neurofibromatosis type 1 with tracheobronchial neurofibromas: case report with emphasis on tomographic findings. J. Thorac. Imaging. 23, 194-196.

Katar, S., Ecer, S., Kervancioğlu, M., Yaramış, A., Özbek, M.N., Devecioğlu, C., 2004. Nörofibromatozisli dört olgunun değerlendirilmesi. Dicle Tip Derg. 31, 42-47.

Kaymak, Y., Yüksel, N., Karabulut, A., Ekşioğlu, M., 2004. Nörofibromatozis: Olgu Sunumu. Türkiye Klinikleri J. Med. Sci. 24, 702-706.

Richardson, M.G., Setty, G.K., Rawoof, S.A., 1996. Responses to nondepolarizing neuromuscular blockers and succinylcholine in VonRecklinghausen neurofibromatosis. Anesth. Analg. 82, 382-385.

Sakai, T., Vallejo, M.C., Shannon, K.T., 2005. A parturient with neurofibromatosis type 2: anesthetic and obstetric considerations for delivery. Int. J. Obstet. Anest. 14, 332-335.

Şahin, A., Aypar, Ü., 2003. Spinal anesthesia in a patient with neurofibromatosis. Anesth. Analg. 97, 1855-1856. 